\title{
Dispositivo de Automação Residencial Usando Princípios de Sistemas Distribuídos
}

\author{
John Lennon Sousa Costa ${ }^{1}$ \\ ${ }^{1}$ Sistemas de Informação - Faculdade de Imperatriz (FACIMP) \\ Imperatriz - MA - Brasil \\ \{John \} lennonsousa@outlook.com
}

\begin{abstract}
Current residential automation systems have been used very often for facilitating the management of various equipment in a residence. However, some of these systems studied in this article are dependent on a centralized control. Another problem analyzed is the difficulty of communication and interaction using different automation systems. Based on this, we propose a control device based on distributed systems using the Arduino prototyping platform. The results show that using such principles the home automation system does not compromise the management of all the equipment in the residence if one of the controllers presents get a failure in its operation.

Resumo. Os sistemas de automação residenciais atuais têm sido usados com grande frequência por facilitar o gerenciamento de vários equipamentos em uma residência. Porém alguns desses sistemas estudados nesse artigo se mostram dependentes de um controle centralizado. Outro problema é a dificuldade de comunicação e interação usando sistemas de diferentes. Baseado nisto, propomos um dispositivo de controle baseado em sistemas distribuidos usando a plataforma de prototipagem Arduino. Os resultados mostram que usando tais princípios o sistema de automação residencial não compromete o gerenciamento de todos os equipamentos na residência caso um dos dispositivos controladores apresente falha no seu funcionamento.
\end{abstract}

\section{Introdução}

"A arquitetura de um sistema domótico, como qualquer sistema de controle, especifica a forma como os diferentes elementos do sistema de controle vão se localizar. Existem duas arquiteturas básicas, arquitetura centralizada e distribuída". [ALIEVI, 2008, p. 16]. Um problema da arquitetura centralizada é caso o controlador pare de funcionar, todos ou parte dos aparelhos da casa controlados por ele, param de funcionar também. Isso torna todo o sistema dependente de um único dispositivo que não dá garantias de disponibilidade integral, comprometendo o bom funcionamento de todo ou parte do sistema de automação residencial.

Os sistemas de automação residencial existentes estão longe de obterem um nível de interação, facilidade de uso e tolerância a falhas satisfatórios aos usuários. O principal problema que ocorre principalmente nos sistemas mais atuais é o uso obrigatório de aplicativos em smartphones, limitando o usuário a tais sistemas operacionais.

No dispositivo proposto, o usuário não precisa baixar qualquer aplicativo ou usar smartphone ou determinado sistema operacional para usar o sistema de automação residencial, isso traz vantagens frente aos sistemas disponíveis no mercado atualmente. 
Existe a necessidade da criação de um sistema que tem a finalidade de automatizar o controle de dispositivos em uma residência que seja independente de qualquer fonte centralizada de controle. Outro problema que tanto a arquitetura centralizada como a distribuída possuem, é a incompatibilidade entre diferentes sistemas e marcas disponíveis no mercado.

A crescente oferta de produtos de fácil utilização, intuitivos e interativos, aplicados à domótica, lançados pelas grandes corporações, pode estar sugerindo, aos projetistas e integradores da automação residencial, que busquem conhecer o modo como que se dá a interação das pessoas nos ambientes automatizados e o que esperam dos dispositivos e sistemas para melhor aplicar a seus cotidianos. [DE AZEVEDO DIAS e PIZZOLATO, 2004, p. 21]. Isso mostra que através do uso de algoritmos e dispositivos programados, pode-se realizar a comunicação entre dispositivos para controlar aparelhos elétricos em uma residência.

Tal algoritmo proposto nesse artigo usa o mesmo conceito de um sistema distribuído, obtendo-se uma maior confiabilidade, pois cada dispositivo pode operar como servidor ou cliente, podendo controlar outros dispositivos além de si próprio.

Este artigo tem como objetivo usar várias tecnologias, protocolos e arquiteturas, que são modelos testados por profissionais da área e usuários comuns, desenvolvendo assim um dispositivo com vários desses conceitos. Todo o sistema não ficará inoperante caso algum nó do sistema pare de funcionar, o usuário pode controlar o sistema através de outro nó.

\section{Trabalhos Relacionados}

O uso de sistemas de automação residencial ou Domótica nas residências, se tornou atualmente um marketing para as construções. As novidades interessam aos mais jovens e a segurança para os mais velhos. Tudo isso é encontrado na automação residencial. [AURESIDE, 2014].

\subsection{Classificação}

A classificação dos sistemas de automação residencial especifica como os componentes serão organizados e distribuídos em todo o sistema.

\subsubsection{Sistemas autônomos}

Sistemas autônomos, são os sistemas em que cada dispositivo na rede é independente e interligado entre si, como explica TEZA [TEZA 2002, p. 31]

"[...] podemos ligar ou desligar um subsistema ou um dispositivo específico de acordo com um ajuste pré-definido. Porém, neste esquema, cada dispositivo ou subsistema é tratado independentemente, sem que dois dispositivos tenham relação um com o outro". [DE AZEVEDO DIAS e PIZZOLATO, 2004, p. 9].

\subsubsection{Sistemas centralizados}

Nesse tipo de sistema existem algumas limitações, como explica TEZA, "A limitação deste sistema está em que cada subsistema deve ainda funcionar unicamente na forma a qual o seu fabricante pretendia. Basicamente, trata-se apenas de controle remoto estendido a diferentes locais" [TEZA, 2002, p. 31]. 
Outro tipo de limitação nesse sistema é a tolerância a erros, ou seja, caso a central de gerenciamento pare de funcionar, todos os aparelhos da residência também param de funcionar, gerando uma pane total no sistema a partir da central.

\subsubsection{Sistema Sonoff}

Um dos mais novos e famosos sistemas de automação residencial que está em evidência pelo público em geral principalmente nas redes sociais, o Sonoff.

Esse sistema de fato é similar em muitos aspectos ao dispositivo de automação proposto neste artigo, sendo ele distribuído, com cada dispositivo controlando um ou até quatro outros aparelhos. É acessado via Wifi por aplicativo ou Cloud service.

Mas apesar de todas essas funcionalidades e preço baixo, ainda assim o dispositivo proposto neste artigo mantém-se superior ao Sonoff por duas questões, primeiro o sonoff se trata de um dispositivo controlado via aplicativo que está disponível nas duas maiores lojas de aplicativos. O usuário conecta o aparelho à rede wifi, e então o roteador transmite todos os dados do sonoff para o aplicativo através de um servidor na INTERNET (ITEAD Intelligent Systems Co. Ltd, 2018). Isso o deixa dependente de plataforma, já que o usuário necessita ter um smartphone com sistema operacional $i O S$ ou Android, o que nos leva a pensar como ficam os usuários que não possuem tal aparelho, ou que possuem um smartphone com sistema operacional diferente, ou se o usuário quisesse usar o sonoff pelo computador?

Segundo, se trata de a aplicação rodar baseada em servidor na nuvem, o que torna todo o sistema dependente de um servidor que pode ou não ter garantias total de funcionamento, deixando o usuário preso a um serviço externo.

\subsection{Sistemas Distribuídos}

"Um sistema distribuído é um conjunto de computadores independentes que se apresenta a seus usuários como um sistema único e coerente". [TANENBAUM e STEEN, 2008, p. $1]$.

\subsubsection{O Uso na Automação Residencial}

Alguns princípios de sistemas distribuídos são aplicados no dispositivo proposto neste artigo. Tais princípios tornam o dispositivo, em alguns aspectos, diferente de outros sistemas da automação residencial já existentes. "Em princípio, também deveria ser relativamente fácil expandir ou aumentar a escala de sistemas distribuídos" [TANENBAUM e STEEN, 2008, p. 2]. Esse princípio se aplica ao dispositivo, pois a complexidade do sistema para o usuário, não aumenta quando é adicionado mais pontos de controle no sistema de automação. "Em geral, um sistema distribuído estará continuamente disponível, embora algumas partes possam estar temporariamente avariadas". [TANENBAUM e STEEN, 2008, p. 2].

Baseado nisso, o dispositivo proposto usa um algoritmo que suporta qualquer computador ou redes diferentes, isso significa que o princípio do algoritmo pode ser implementado em qualquer tipo de computador/controlador usando qualquer tecnologia, basta apenas está ligado na mesma rede, que pode ser cabeada usando o padrão Ethernet ou pode ser uma rede sem fio, o que facilita ainda mais a instalação do dispositivo.

O dispositivo proposto nesse artigo será classificado como um sistema autônomo e com características de sistema distribuído. 


\subsection{Comunicação entre os sistemas}

Em todos os sistemas de automação residencial, cada dispositivo integrante da rede deve comunicar-se com os outros, enviando um comando e/ou uma solicitação. Para tal tarefa, são usados protocolos de comunicação, que atualmente são dos mais variados tipos e tecnologias, cada um com o seu ponto forte e ponto fraco, mas sempre resolvendo problemas de casos e necessidades especificas. "[...] faz-se necessária a instalação de sistemas e de protocolos apropriados que permitam garantir a conectividade e integração entre as múltiplas funcionalidades dos dispositivos da instalação doméstica" (DE AZEVEDO DIAS; PIZZOLATO, 2004, p. 12).

De acordo com TEZA existem alguns protocolos usados para a comunicação em sistemas de automação residencial, entre os mais importantes estão:

\subsubsection{Sistema $\mathrm{X}-10$}

Realiza a comunicação através da linha elétrica 110v ou 220v. Por essa característica de funcionar através do cabeamento já existente, o protocolo X-10 é indicado para sistemas de automação distribuídos (TEZA, 2002). Porém possui algumas limitações, opera apenas funções básicas de liga/desliga e dimerização de luzes, as anomalias e descargas eletromagnéticas na rede podem causar erros de comportamento nos dispositivos, e possui uma confiabilidade limitada por ser caro e complexo a implantação de sistemas que monitoram o status dos dispositivos.

\subsubsection{Sistema lonworks}

Possui características importantes, como a interoperabilidade, serve para diversos produtos de diferentes fabricantes e aplica-se a sistemas distribuídos. A comunicação entre os "Nós" é feita através do protocolo Lontalk. A rede é formada por vários dispositivos independentes e com inteligência própria, cada nó pode se comunicar com sensores e atuadores sem necessitar de um gerenciador central. (DE AZEVEDO DIAS; PIZZOLATO, 2004).

\subsubsection{Sistema IHC}

O IHC adota a arquitetura centralizada para o seu funcionamento. “[...] os circuitos que derivam dos diversos dispositivos distribuídos na instalação, são conduzidos a um local e conectados aos equipamentos de gerenciamento e controle que lá se encontram". (DE AZEVEDO DIAS; PIZZOLATO, 2004, p. 22).

\section{Arduino ${ }^{\mathrm{TM}}$}

Para o desenvolvimento do dispositivo de automação residencial proposto neste artigo, será usado o micro controlador Arduino. "Em termos práticos, um Arduino é um pequeno computador que você pode programar para processar entradas e saídas [grifo nosso] entre o dispositivo e os componentes externos conectados a ele" [MCROBERTS, 2011. p. 22].

Uma função muito importante no dispositivo de automação proposto é a sua acessibilidade por meio da rede local de computadores da residência, como é um dispositivo autônomo ele tem o seu próprio processamento, então ele aceita requisições de clientes, sendo um servidor e também envia requisições a outros dispositivos de automação presentes na casa, sendo também um cliente na rede. Para se obter tal função, será usado a placa de apoio Ethernet Shield ou a WiFi Shield. Dessa forma está montado 
um micro controlador programado para processar requisições e então acionar aparelhos na residência, tudo isso acessado via rede local ou INTERNET, na Figura 1 são representadas as placas.

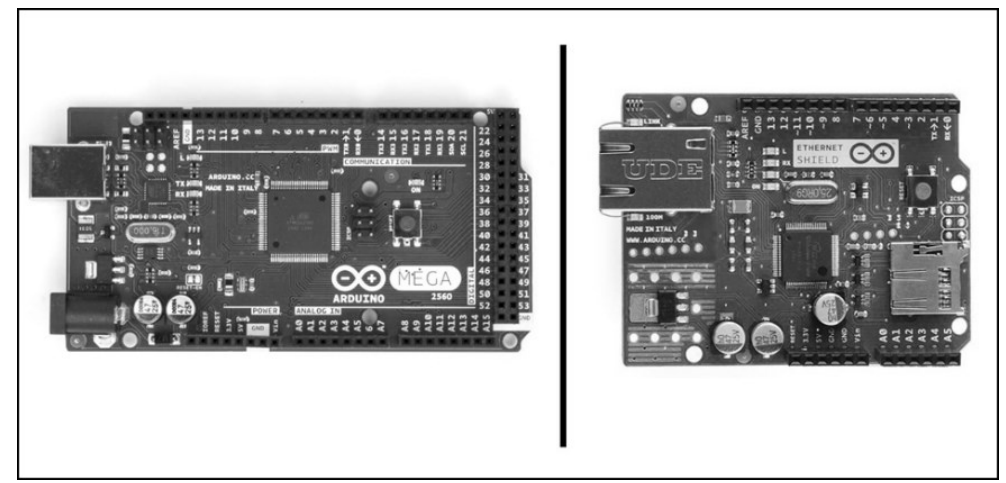

Figura 1- Micro controlador Arduino Mega 2560 e Ethernet Shield

\section{Desenvolvimento do Dispositivo}

Para uma melhor análise do dispositivo de automação desenvolvemos um cenário com uma casa com cinco cômodos e três dispositivos de automação controlando as luzes de cada ambiente e uma cortina automatizada, como mostra a Figura 2.

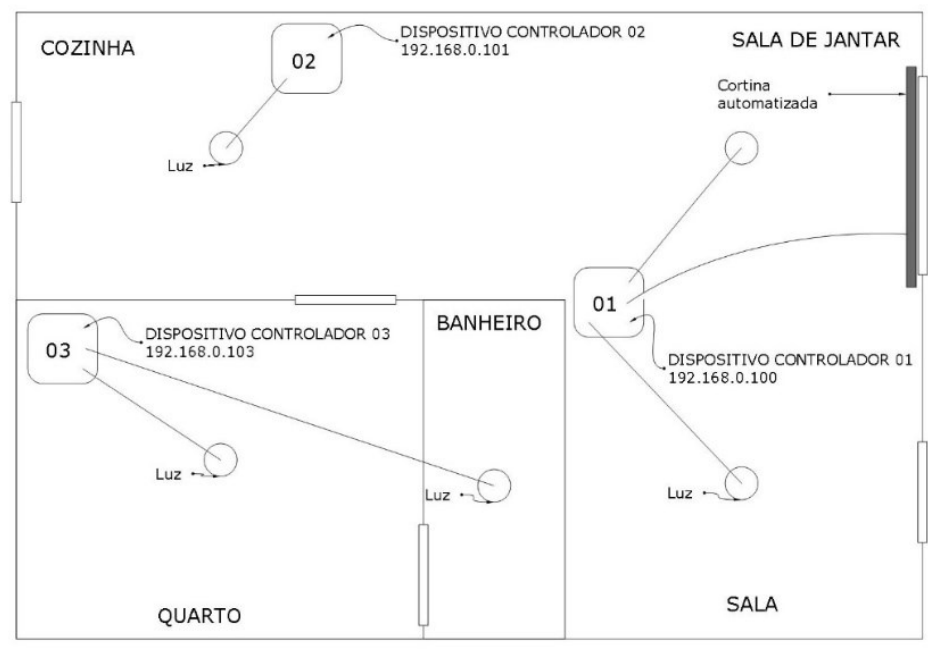

Figura 2 - Representação da casa com os dispositivos

Nesse cenário temos dois tipos de dispositivos, o dispositivo controlador, que é o responsável por receber comandos via rede local, processar esses comandos e realizar uma ação, o dispositivo controlado é o aparelho do cotidiano na casa que vai ser controlado pela automação, podendo ser uma luz de teto, abajur, ar-condicionado, etc. Esse, portanto recebendo a ação do dispositivo controlador.

Os dispositivos controladores na casa podem controlar um ou mais aparelhos (luzes, ar-condicionado, cortina, etc), porém neste artigo iremos abordar o controle apenas de dois aparelhos por dispositivo controlador. Cada dispositivo controlador tem um endereço IP único, estes também conhecem os endereços dos outros conectados na rede, podendo se comunicar, enviar comandos de liga e desliga ou requisitando o status para saber se o aparelho controlado está ligado ou desligado. Existem basicamente quatro 
partes principais para o funcionamento do dispositivo controlador, entrada de alimentação, arduino, relés e saída.

\subsection{Entrada}

Aqui é onde o dispositivo controlador é alimentado para funcionar, logo após a corrente é reduzida para 9 volts para alimentar o arduino.

\subsection{Arduino}

É onde todas as requisições serão processadas de acordo com as solicitações dos usuários. É onde o algoritmo roda, analisando todos os procedimentos programados.

\subsection{Relés}

É o dispositivo que vai controlar a alimentação dos aparelhos controlados, podendo desliga-los ou liga-los, de acordo com as solicitações dos usuários do sistema de automação.

\subsection{Saídas}

Aqui os dispositivos controlados serão conectados para serem acionados ou desligados.

O esquema do dispositivo controlador é representado na figura 3.

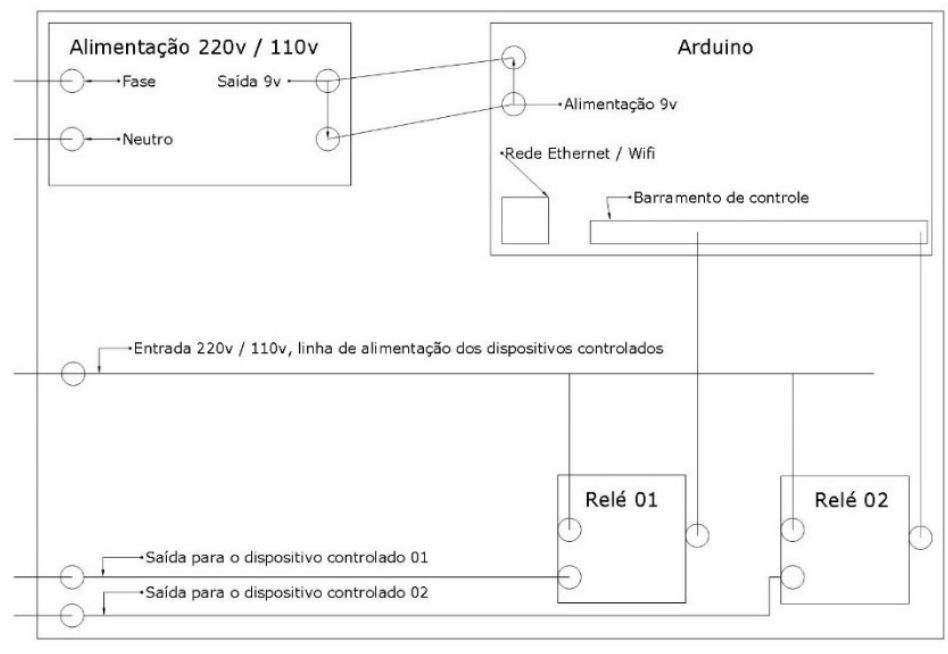

Figura 3 - Representação de funcionamento do dispositivo controlador

\section{Desenvolvimento o Conceito do Algoritmo}

Essa é a parte mais importante de todo o projeto, sendo ela responsável por todo o gerenciamento de requisições e respostas.

Para o usuário acessar o sistema de automação residencial ele precisa acessar um dos dispositivos controladores, cada um possui um endereço IP na rede, porém ele precisa conhecer apenas o endereço de um dispositivo controlador, pois o mesmo dispositivo acessa os outros na rede e mostra a situação de cada um na tela de retorno. Nesse artigo não será discutido o registro de nome de domínio para facilitar a memorização do endereço do dispositivo na rede, apenas será considerado o endereço 192.168.0.100 para acessar um dos dispositivos, o acesso é feito via navegador web, o dispositivo controlador retorna uma página $\mathrm{html}$. O usuário pode acessar os dispositivos controladores de 
qualquer aparelho, seja computador, smartphone, tablet e de qualquer sistema operacional, sendo o sistema independente de plataforma.

O algoritmo funciona em um loop, aguardando solicitações HTTP de usuários. Ao receber uma conexão de um cliente na rede, o algoritmo analisa todas as solicitações HTTP feitas para o dispositivo controlador. É feita uma análise letra por letra para saber qual comando foi dado (falaremos mais a frente sobre tais comandos). Porém no primeiro acesso de cada usuário do sistema, a solicitação HTTP vem sem nenhum comando, então o algoritmo apenas responde para o usuário com uma tela mostrando todos os aparelhos controlados pelo sistema de automação.

Inicialmente o sistema inicializa as variáveis de controle, logo em seguida entra em um loop, dentro desse estado de repetição contínua, o sistema aguarda por uma solicitação de algum cliente que queira usar o dispositivo de automação residencial através da rede local de computadores. Quando um cliente se conecta ao servidor, o texto da requisição do cliente é armazenado em uma variável global e é processado, então o sistema envia uma resposta para o cliente e aciona através dos relés o aparelho do sistema de acordo com a solicitação do cliente.

Ao acessar o sistema, o usuário visualizará a seguinte tela como mostra a figura 4:

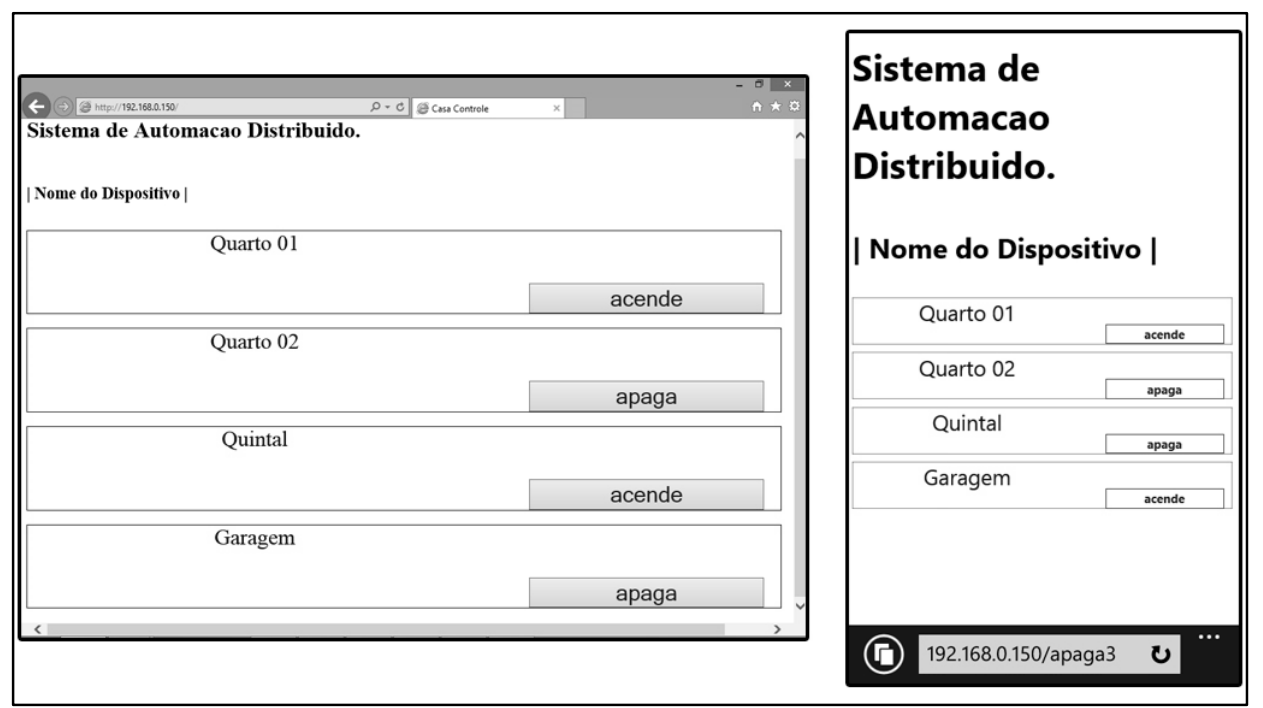

Figura 4 - Páginas web geradas pelo dispositivo de automação, em um navegador de computador de mesa e em um outro navegador de um dispositivo móvel.

Para algum usuário acessar o sistema de automação residencial, ele primeiro precisa saber o endereço na rede de um dos dispositivos controladores que compõem o sistema de automação. Como já havíamos mencionado, não discutiremos nesse artigo o registro de nome de domínio para facilitar a memorização do endereço do dispositivo na rede, apenas será considerado o endereço 192.168.0.100 para acessar um dos dispositivos. O sistema pode ser composto por qualquer quantidade de dispositivos controladores (um ou mais), cada um podendo controlar um ou mais aparelhos na casa (luz, ar-condicionado, cortinas automatizadas, etc).

\subsection{Processando Solicitação}


Esse é um processo muito importante do algoritmo, é nessa parte onde a requisição vinda do cliente é analisada e processada. Essa rotina é dividida em quatro partes de análises: /acende, /apaga, /status e /. O algoritmo procura pela palavra depois da "/" (barra) do GET.

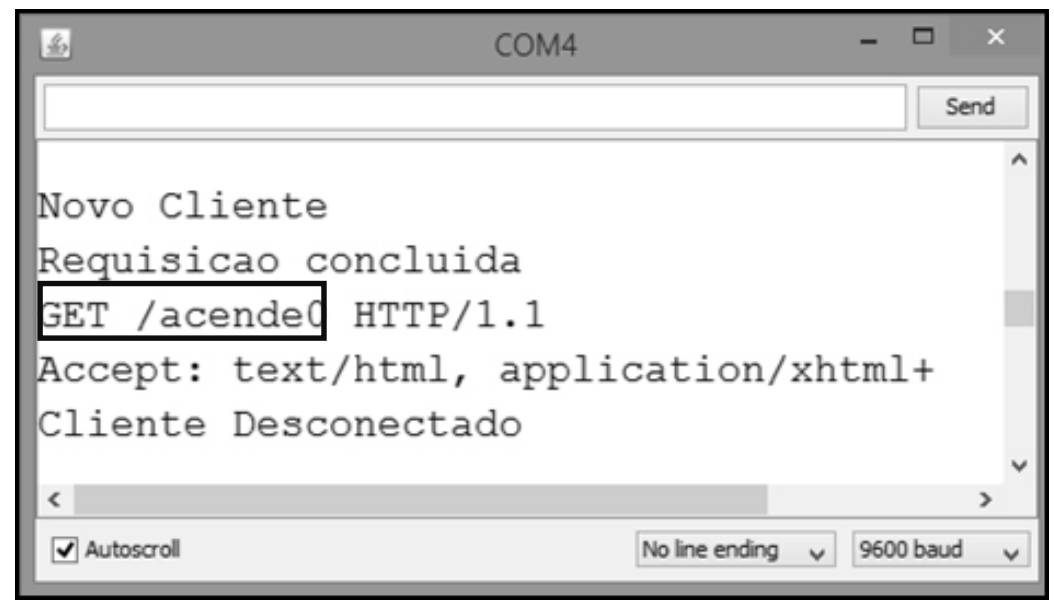

Figura 5 - Requisição GET http mostrada na saída serial do arduíno.

\subsection{Comando apaga, acende e status}

$\mathrm{Na}$ figura acima vemos a saída gerada por um dispositivo controlador ao receber uma solicitação de algum usuário. Toda solicitação vem acompanhada de um GET, que serve para enviar alguma instrução via protocolo HTTP. O algoritmo analisa o GET após a barra e verifica se encontra algum comando. Um comando é gerado quando o cliente clica em algum botão na página gerada pelo dispositivo controlador, ao clicar no botão "acende" é gerada uma solicitação GET /acende e ao clicar no botão apaga é gerado um GET lapaga. Ao encontrar "/acende" ou "/apaga", é verificado qual o número vindo após o comando, esse número corresponde a qual aparelho vai ser enviado o comando de apaga ou acende. Essa lista é gerada automaticamente pelos dispositivos controladores e compartilhadas entre si, cada aparelho controlado na casa tem um número. Ao encontrar o número do dispositivo correspondente, o dispositivo de automação se torna um cliente e então envia uma requisição HTTP ao dispositivo que corresponde ao número encontrado no comando do GET.

É de extrema necessidade que o usuário ao acessar o dispositivo de automação residencial, seja possível verificar a situação dos outros dispositivos ligados na rede da residência, isso aumenta a usabilidade do sistema. Para tal funcionalidade existe o comando "status", que é executado de um dispositivo para outro. Toda vez que um dispositivo controlador é acessado por um usuário, esse dispositivo precisa retornar uma tela com todos os aparelhos controlados e seus status, se estão ligados ou desligados. Para isso, o dispositivo controlador envia uma requisição HTTP GET /status para todos os outros dispositivos controladores da casa e cada um responde com 0 (zero) para desligado ou 1 (um) para ligado.

Tal procedimento funciona enviando uma requisição de status para cada endereço IP dos outros dispositivos de automação ligados à rede. Quando a requisição de status é enviada, o algoritmo aguarda por vinte vezes a resposta do dispositivo. Só assim é gerada a página para o usuário com todos os aparelhos e seus status. 

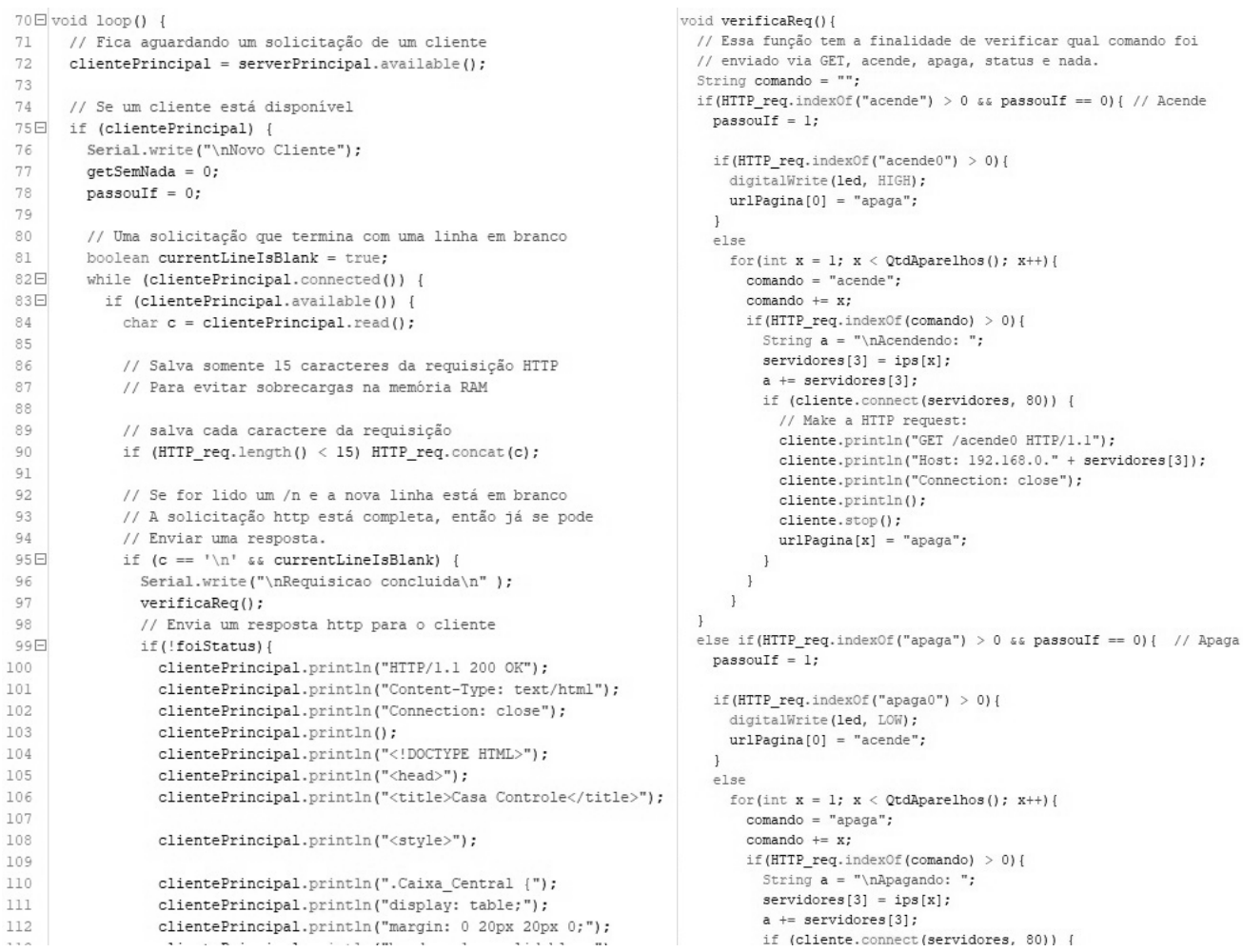

Figura 6 - Trechos do algoritmo que mostra a análise de uma solicitação e dos comandos.

\section{Controlando os Outros Dispositivos}

Para controlar outros aparelhos na casa ligados a outros dispositivos controladores, o usuário não precisa sair acessando todos um por um, essa tarefa é feita por um único dispositivo controlador que já tem a lista de todos os outros controladores na casa e se comunica com eles enviando comandos HTTP de acordo com os botões que o usuário clica.

Se o usuário acessou o dispositivo controlador número 03 de IP 192.168.0.103 e quer desligar a lâmpada da sala que está conectada no dispositivo controlador número 01 de IP 192.168.0.100, ele não precisa acessar o 01, basta ele acessar o 03 e a partir daí clica no botão correspondente a lâmpada da sala conectada no controlador 03 .

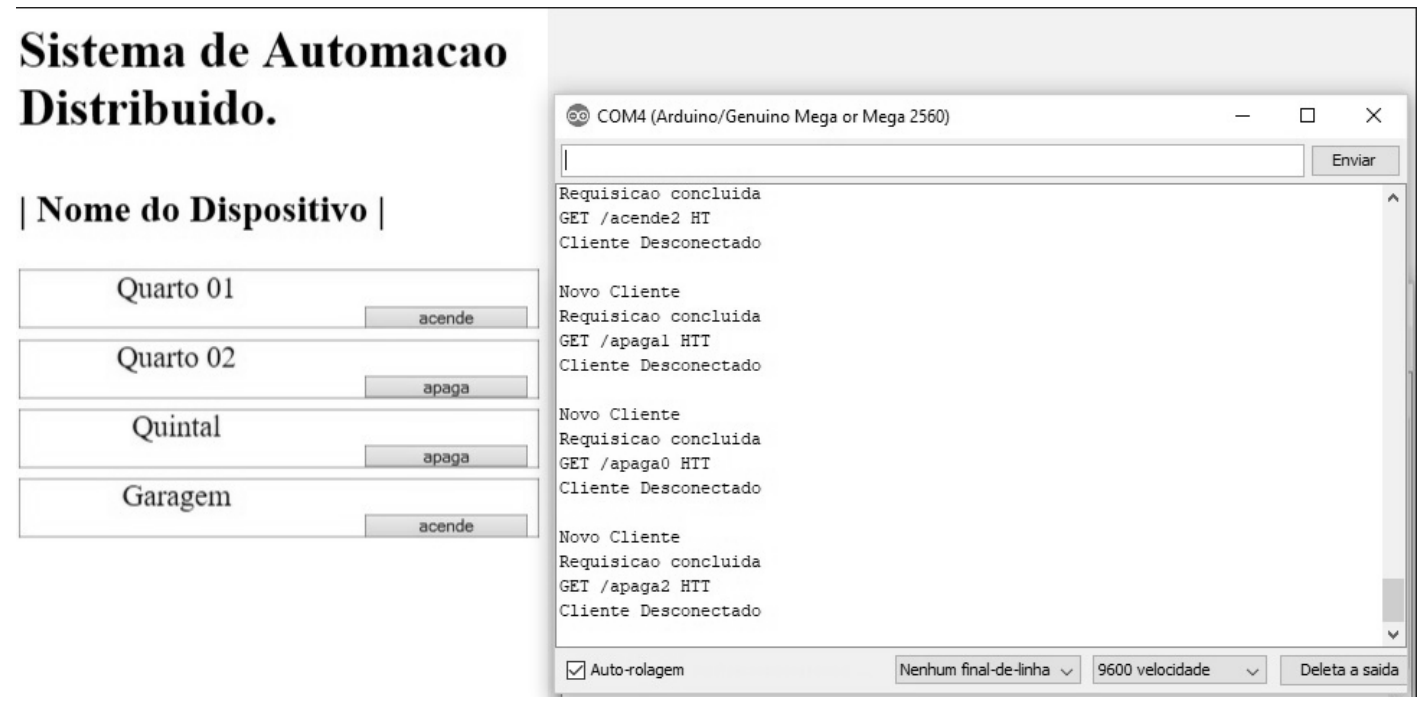


Figura 7 - Saídas na porta serial do arduíno mostrando o resultado de algumas solicitações.

$\mathrm{Na}$ figura acima temos um exemplo dessas solicitações feitas pelo usuário ao clicar em um botão na página web do dispositivo controlador. Podemos observar vários "GET" com os comandos "apaga" ou "acende" seguido do identificador do aparelho controlado.

\section{Instalação}

A instalação do dispositivo de automação residencial é feita apenas ligando-o na rede elétrica. $\mathrm{O}$ aparelho que será gerenciado pelo dispositivo é ligado na saída gerenciada e o dispositivo é ligado à rede de computadores através da interface Ethernet ou por meio da rede sem fio. O diagrama de instalação é mostrado na figura 8.

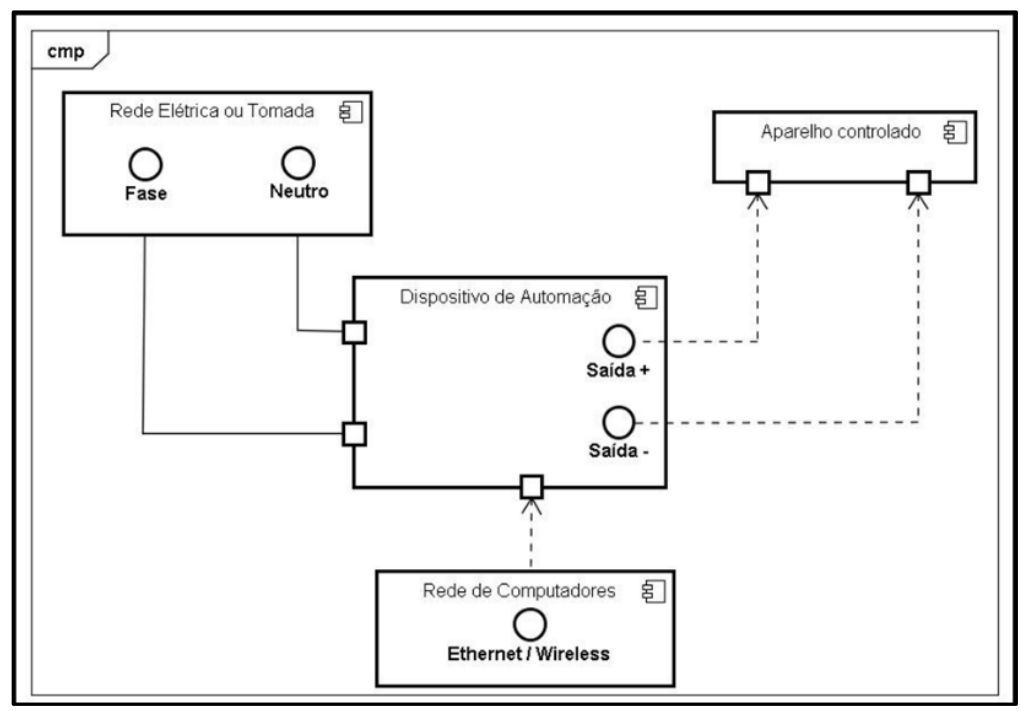

Figura 8 - Diagrama de instalação.

\section{Resultados}

Com a apresentação do conceito de dispositivo de automação residencial usando conceitos de sistemas distribuídos foi possível obter-se resultados satisfatórios em relação aos outros sistemas disponíveis atualmente no mercado.

O dispositivo é capaz de ser acessado via navegador web por qualquer tipo de sistema operacional, sendo independente de plataforma e navegador. Não sendo necessário o uso de aplicativos para gerenciar os aparelhos na casa e nem de serviços externos como servidores em nuvem.

Ao ser acessado pela primeira vez, o dispositivo faz uma busca na rede solicitando os status de todos os outros aparelhos controlados por outros dispositivos, isso torna o sistema equiparável a sistemas distribuídos. 


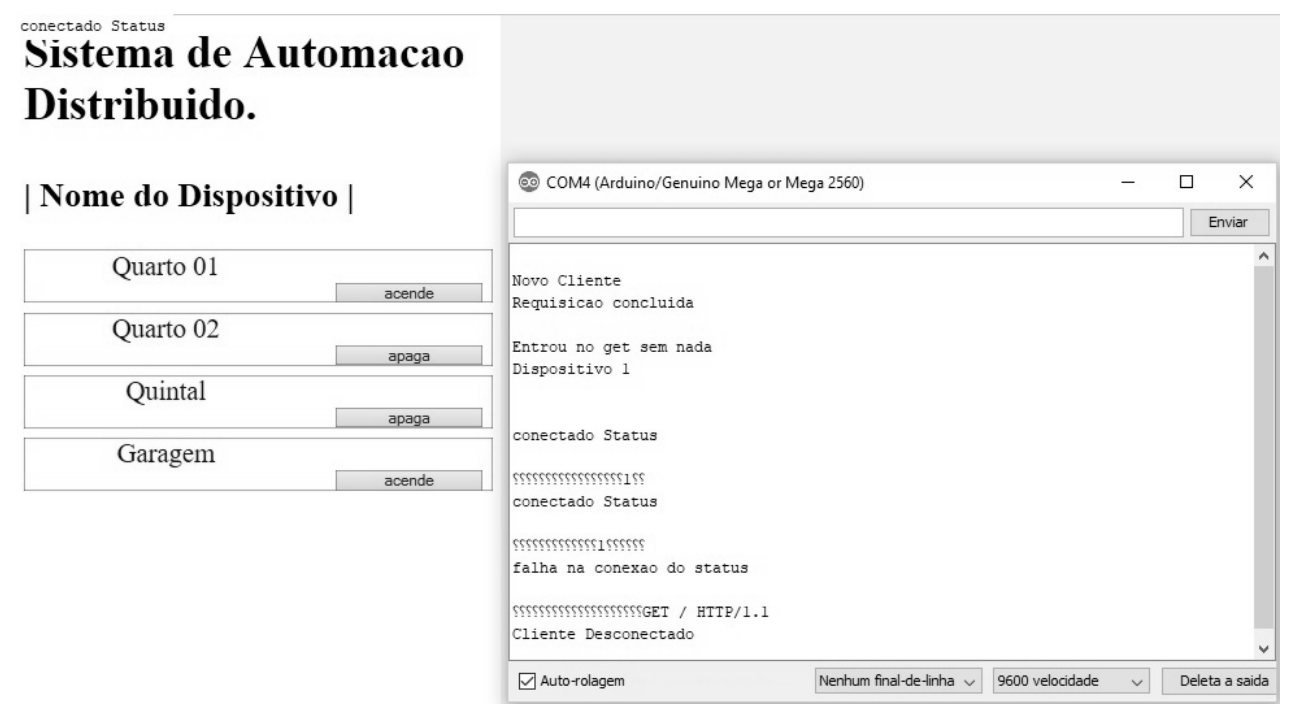

Figura 9 - Página web gerada contendo todos os aparelhos na casa com seus respectivos status.

Podemos observar na figura acima que ao ser acessado pela primeira vez, o sistema reconhece o GET/, que é chamado internamente de "get sem nada", dessa maneira o sistema entende que precisa acessar os outros dispositivos na casa e verificar os status dos aparelhos, então ele envia um GET/status para todos os dispositivos controladores para obter a situação de cada aparelho na casa. Se houver falha em receber um status de algum dispositivo, o algoritmo apenas segue em frente e não solicita mais ao dispositivo, isso torna o sistema independente de falhas, mesmo se alguns nós estejam com problemas.

\section{Trabalhos Futuros}

A ideia proposta neste artigo mostra um futuro promissor para tal dispositivo, podendo ser barato para se construir e fácil de operar. Porém ainda existem possíveis melhorias para tal ideia.

Um incremento interessante seria a criação de um algoritmo capaz de tornar o dispositivo compatível com resolução de nome de domínios, pois é bem mais fácil um usuário acessar o dispositivo com um nome "minhacasa.eu" do que por um endereço IP. Também seria interessante criar um uma adaptação para ligar o dispositivo à uma tomada normal na casa, para além de gerencia o aparelho pelo celular, também ser possível de ligar ou desligar através do modo convencional, pela tomada na parede.

Há vários possíveis incrementos no dispositivo, como por exemplo a possibilidade de alteração dos nomes de cada aparelho controlado e também a classificação e agrupamento de diferentes tipos de aparelhos e em diferentes grupos de locais, como aparelhos da cozinha, aparelhos do quarto, etc.

\section{Conclusão}

O dispositivo de automação residencial apresentado neste artigo pode oferecer vantagens frente aos demais sistemas de automação residencial disponíveis no mercado, pois sua arquitetura descentralizada oferece uma maior confiabilidade contra erros, pois cada dispositivo usa princípios de sistemas distribuídos, por esse motivo, o usuário controla todos os dispositivos e aparelhos da casa acessando apenas um dispositivo de automação. 
Caso ocorra travamentos ou qualquer outro tipo de avaria no dispositivo, o usuário escolhe um outro para acessá-lo e gerenciar os aparelhos da casa, basta acessar outro endereço IP que será mostrado todos os dispositivos controladores funcionado na casa.

Conclui-se que o desenvolvimento e implantação de um dispositivo de automação residencial distribuído discutido nesse artigo é viável, pois sua facilidade em desenvolver, programar, implantar e manter é bem maior do que comparado com os sistemas de automação encontrados atualmente. $\mathrm{O}$ gerenciamento por parte do usuário, pode ser feito independentemente de qualquer sistema operacional ou aparelho, podendo ser acessado por meio de celulares, smartphones, tablets, computadores e etc.

No artigo foi proposto uma ideia de algoritmo que pode ser desenvolvido em qualquer tipo de linguagem para qualquer chip controlador. $\mathrm{O}$ ponto principal do artigo foi atingido que é perspectiva de uma ideia original e viável, que pode ser posteriormente implementada em um algoritmo e usada em uma placa de circuito integrado para assim desenvolver um dispositivo controlador para formar um sistema de automação residencial.

\section{Referências}

Itead, Intelligent Systems Co. Ltd. (2018) "Sonoff Smart Home". http://sonoff.itead.cc/en/, Julho.

Alievi, César Adriano (2008) Automação Residencial Com Utilização De Controlador Lógico Programável, Rio Grande do Sul, Novo Hamburgo.

Arduino, (2014) "Products", http://arduino.cc/en/Main/Products, Agosto.

De azevedo dias, César Luiz e Pizzolato, Nélio Domingues (2004) Domótica em Aplicabilidade e Sistemas de Automação Residencial, v. 6, n. 3, p. 9-32. Vértices.

Mcroberts, Michael (2011) Arduino Básico, São Paulo. Novatec.

Tanenbaum, Andrew; STEEN e Maarten (2008) Sistemas Distribuídos em Princípios e Paradigmas, Pearson Education, p. 1-2, $2^{\mathrm{a}}$ ed, São Paulo.

Teza, Vanderlei Rabelo (2002) Alguns aspectos sobre a automação residencial, 106f, Dissertação (Mestrado em Ciência da Computação), Faculdade de Ciência da Computação, Universidade Federal de Santa Catarina, Florianópolis. 